\title{
NATURALEZA FONÉTICA DE LA CONSONANTE 'YE' EN ESPAÑOL
}

\author{
PHONETIC NATURE OF THE CONSONANTE 'YE' IN SPANISH
}

\author{
Eugenio MARTíNEZ CELDRÁN
}

Facultat de Filologia, Universitat de Barcelona

\section{RESUMEN:}

En la RAE (2011) se habla del fonema /j/ y, en la página 174, se dice que es un sonido fricativo sonoro. En el CD que acompaña esa Fonética y Fonología se afirma que la consonante /j/ se realiza habitualmente fricativa prepalatal. Y las variantes que se admiten son además de la fricativa, una variante africada y otra más que carece de fricación y que se transcribe /J/. Navarro Tomás (1946) decía que «la $y$ de mayo, con pronunciación suave, africada o rehilante, constituye igualmente una sola unidad fonológica» (p. 9). En esta afirmación, Navarro no utiliza el término «fricativa», sino que habla de variantes «suaves» y «rehilantes». En un artículo anterior sobre el rehilamiento (1934) ya había dejado claro que las fricativas son los sonidos que poseen rehilamiento; por tanto, las rehilantes son para él las fricativas y lo que actualmente llamamos aproximantes son las suaves. Y él admitía que la consonante 'ye' podía tener esos tres alófonos. Nuestra pretensión en este estudio es demostrar, no solo que existe la variante aproximante, sino que, además, es el alófono más habitual. Para ello se utiliza un método que mide de forma especial el ruido existente en la pronunciación de un sonido. Se trata de los cruces por cero. La conclusión final confirma nuestra hipótesis: la pronunciación más normal de la consonante ye española es aproximante.

PALABRAS CLAVE: ye, consonante, naturaleza fonética

\section{ABSTRACT:}

When RAE (2011:174) deals with the phoneme / $\mathrm{j} /$, it says that is a voiceless fricative sound. The CD that goes with the Fónetica y Fonología states that the consonant $/ \mathrm{j} /$ is usually produced as a fricative prepalatal. And the allowed variants (besides the fricative) are an affricate variant and a non-fricative variant that they transcribe as /y/. Navarro Tomás (1946: 9) said, «the y from mayo, with a smooth, affricate or rehilante pronunciation constitutes a single phonological unit». In this statement Navarro Tomás does not use the term «fricative» but he speaks of «smooth» and «rehilantes» variants. In previous work about fricatives (1943) he maintained that fricatives are sounds that have «rehilamiento» (what has been called in English tradition a turbulent airstream); thus, the rehilantes are the fricatives and what we call nowadays approximants are smooth consonants. He admitted that the consonant 'ye' could have those three allophones. The aim of this paper is to prove both that the approximant variant exists and that is the most used allophone. In order to do so, we use a method that measures the existing noise in the sound production in a special way. It is known as zero-crossing. The final conclusion confirms the hypothesis: the more usual production of the Spanish consonant 'ye' is approximant and palatal.

KEY WORDS: ye, consonant, phonetic nature 


\section{PRESENTACión}

Todavía son muchos los autores que consideran que el sonido más habitual de la consonante 'ye' española posee fricación y, por tanto, debe ser considerada una fricativa. En la RAE (2011), a pesar de generalizar ya la consideración de aproximantes de /b, d, $\mathrm{g} /$ en los contextos apropiados, cuando habla del fonema /j/, en la página 174 , se dice lo siguiente: "A los segmentos fricativos mencionados, hay que añadir el fricativo sonoro /j/...». En el CD que acompaña esa Fonética y Fonología, titulado Las voces del español se dice que "la consonante / $\mathrm{j} /$ se realiza habitualmente fricativa prepalatal" (se encuentra en 'Sonidos del español; las consonantes fricativas'). Y las únicas variantes que se admiten son además de la fricativa, una variante africada y una que no se clasifica y que dicen que carece de fricación y que se transcribe $/ \mathfrak{J} /$, el símbolo representa, aunque no se diga, una oclusiva palatal sonora. Como se ve no se habla para nada del alófono aproximante. No obstante, en el texto del libro se dice (en la página 193): «posee un alófono aproximante [j], uno fricativo [j] y otro africado [ $\widehat{\mathrm{dj}}]$ ». Dos cuestiones: una primera nos lleva a considerar que no ha habido una verdadera coordinación y la intervención de diferentes autores hace que existan estas divergencias, en el libro de la RAE. Una segunda cuestión es la utilización del símbolo /j/. Es cierto que en el IPA se dice que es una aproximante, pero es que también lo son las semiconsonantes/semivocales; sin embargo, tratándose de una consonante lo más exacto es utilizar el símbolo de la fricativa con el diacrítico de abertura [j'], como se hace con las demás consonantes aproximantes.

Entre los autores más recientes, Quilis (1981: 221-225), en el apartado sobre las Fricativas de Resonancias Bajas dice sobre la [u]]: «estas constrictivas han sido emitidas con un grado de estrechamiento que no ha llegado en ningún caso a la fricación llamada "rehilada"»; (y en 1981: 256) este autor dice que hay una africada «alófono del fonema

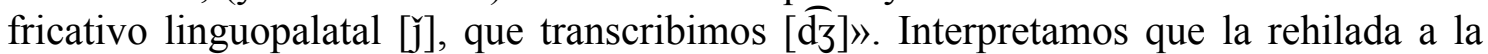
que se refiere Quilis es [3], por tanto la 'ye' intervocálica no llega a ser este otro tipo de fricativa; pero en todo caso, para él sigue siendo fricativa, aunque hable de resonancias bajas. Si nos atenemos al sentido original que Navarro Tomás (1934) dio al término 'rehilamiento', todas las fricativas lo poseen. Es cierto que más tarde muchos autores lo restringieron a la fricativa postalveolar rioplatense [3]. Nosotros seguiremos el sentido original, toda fricativa es por principio rehilante, como decía Navarro Tomás. Quilis no admitió en ningún momento la denominación «aproximante», solo hizo una distinción entre fricativas de resonancias bajas y altas, pero al fin y al cabo fricativas. Y entre los autores más modernos, algunos que sí admiten las aproximantes, como Face (2003: 26), que dice «in other positions $/ \mathrm{b}, \mathrm{d}, \mathrm{g} /$ are realized as voiced approximants»; sin embargo a continuación (p.27) indica respecto a /j/ que «the most common pattern is a palatal fricative pronunciation»».

En otros muchos encontramos ambivalencias. Canellada y Kuhlmann (1987) exponen en dos cuadros este sonido. En p. 21, aparece como fricativa palatal sonora, en un cuadro sinóptico de fonemas y archifonemas con sus variantes. En p. 36, en un cuadro consonántico, la colocan como aproximante sonora mediopalatal. Como se ve no acaban de decidirse por una sola consideración. Hualde (2014: 162) dice: «en este libro 
usamos el símbolo / j / para referirnos a una consonante palatal sonora de constricción

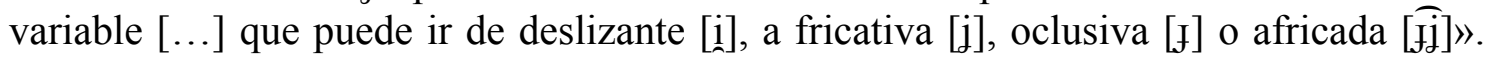
Pero a continuación indica que «la realización más común en la norma peninsular es fricativa palatal sonora débil o una consonante aproximante [j] [...]» Aquí habría que explicar qué significa 'débil'. En la bibliografía fonética más habitual no se habla de fricativas débiles

Después del artículo sobre el «rehilamiento» (1934), Navarro Tomás admitió la existencia de tres posibles realizaciones del segmento que él transcribe /y/: «la $y$ de mayo, con pronunciación suave, africada o rehilante, constituye igualmente una sola unidad fonológica» (1946: 9). Ya no aparece el término fricativa y, en cambio, introduce la denominación 'suave' opuesta a rehilante. Esta última es claramente la fricativa, por tanto la 'suave' ha de ser forzosamente la que actualmente se denomina 'aproximante'.

Hasta ahora ningún autor ha proporcionado datos sobre el uso de unas u otras variantes. Parece que Aguilar (1997: 88) es la primera que proporciona datos al indicar que «en cuanto a la sílaba Consonante palatal + vocal, se han observado realizaciones fricativas y aproximantes con una frecuencia de aparición del 11,25\% y el 88,75\%, respectivamente... En todos los contornos vocálicos se da un predominio de la aproximante [...]»; es decir, para esta autora en un 88,75\% se encuentran aproximantes en el sonido consonántico de la 'ye'. Es un porcentaje altísimo y demuestra que no tienen razón todos aquellos que siguen afirmando que es un sonido principalmente fricativo. Son las aproximantes los sonidos mayoritarios por lo que debe considerarse que es la realización más habitual. Los autores del libro publicado por la RAE no han tenido en cuenta el trabajo de L. Aguilar. Y menos los que confeccionaron el CD que lo acompaña. No solo se equivocan en decir que este sonido es fricativo, sino también en afirmar que es 'prepalatal'. La mayor parte de autores dicen que es palatal, como se acaba de ver en las distintas citas expuestas. Incluso Canellada y Kuhlmann (1987) la clasifican como mediopalatal. Los electropalatogramas (Martínez Celdrán y Fernández Planas, 2007: 87 y 168) demuestran que efectivamente son mediopalatales, pues los contactos se concentran en las filas 6 y 7 de los electropalatogramas, que es una zona plenamente palatal. La figura 1 compara la realización de la africada [t $[\mathrm{f}]$ y la doble articulación de la [jj]'], la primera es una verdadera alveolopalatal y los contactos se centran en las filas 2, 3 y 4 que corresponden a zona alveolar, mientras que la segunda los posee en 5, 6 y 7 que es la zona propiamente palatal. Por tanto, es una articulación

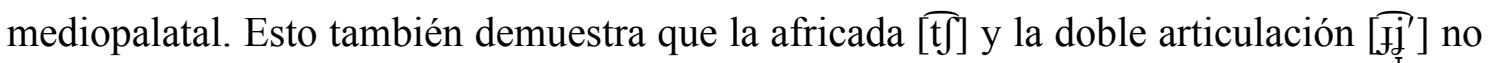

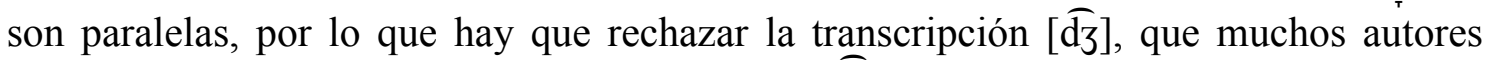

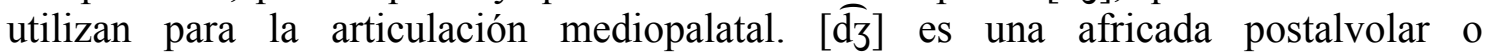

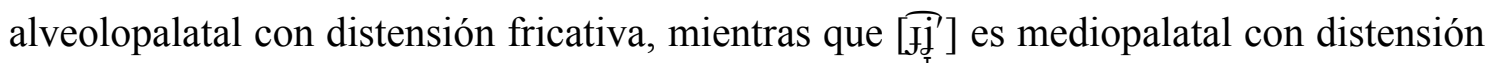
aproximante de forma habitual, de ahí que más que una africada deba ser tratada como doble articulación, si admitimos que cualquier africada ha de poseer distensión fricativa. Lo que estamos diciendo de las articulaciones africadas o dobles sirve para la fricativa y la aproximante correspondientes. 


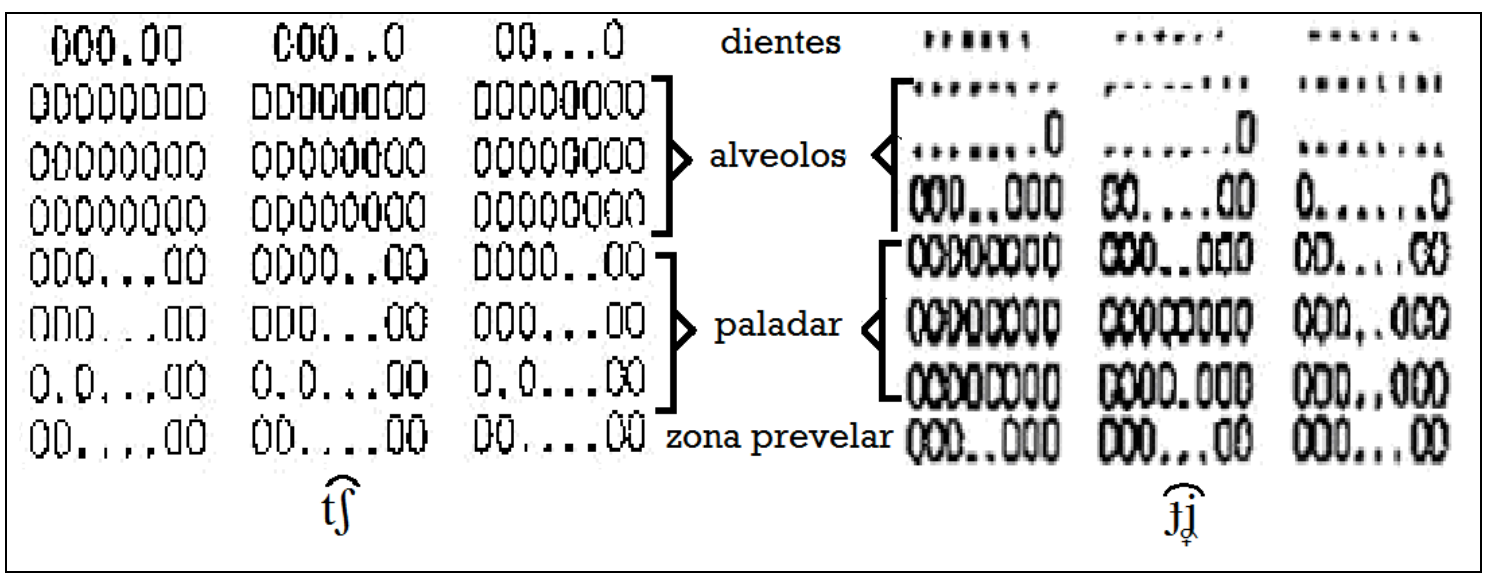

Fig. 1. Electropalatogramas que muestran el punto de articulación mediopalatal de la consonante 'ye'

Todavía debemos establecer otra distinción importante para delimitar la naturaleza fonética de la consonante ye. Se trata de distinguir claramente la semiconsonante o semivocal de la consonante. Hace muchos años, en 1895, Saroïhandy ya indicó que la confusión entre esos dos sonidos no era aceptable: $\langle\boldsymbol{u}\rangle$ en bueno e $\langle i>$ en bien son, sobre todo, vocales asilábicas, mientras que $<(h) i>$ - en hierba y $<(h) u>$ - en hueso son verdaderas consonantes, defendía este autor. Por esta razón, sugirió la transcripción bien y bŭeno; yerba y weso, respectivamente. Mucho más recientemente, Recasens (2014: 129) indica que «una diferència remarcable entre $/ j, w / i[\beta, ð, j, \gamma]$ és que les dues primeres aproximants no són prolongables en el temps mentre que les quatre segones ho són (vegeu però Maddieson, 2008) [...]» Pero si vamos a un espectrograma, las diferencias son palpables (fig. 2).

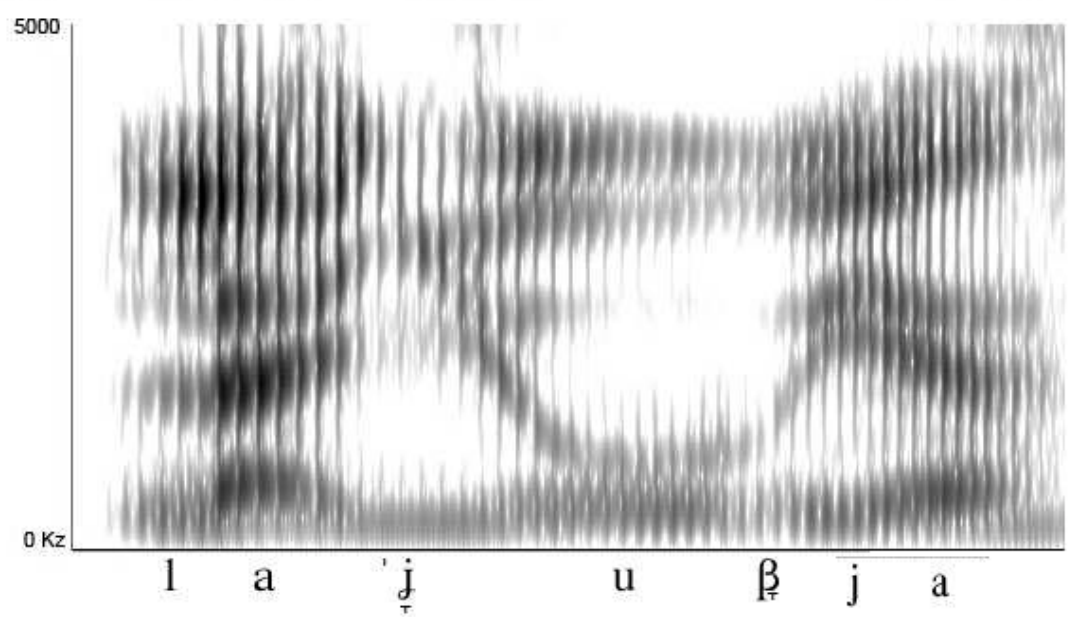

Fig. 2. Diferencia espectrográfica entre una consonante ye aproximante y una semiconsonante

En el espectrograma de la lluvia (figura 2), con pronunciación yeísta, se ve que la consonante aproximante posee un F2 debilitado, aunque todo el sonido es más débil que 
las vocales que lo rodean, mientras que la semiconsonante del diptongo mantiene su estructura formántica plena aunque se muestra como un sonido transitorio hacia la vocal plena (véase Martínez Celdrán, 2008).

\section{MÉTODO}

\subsection{Grabación}

Se grabaron cuatro hablantes femeninas. Cada hablante pronunció tres frases en las que la palabra inicial era la que contenía el sonido que pretendíamos estudiar. La frase portadora era «...es una palabra». Se colocaba en el inicio de la frase para obtener pronunciaciones con doble articulación tras el silencio absoluto en las palabras que comenzaban ortográficamente con $<$ hi- $>$. Se realizaron tres repeticiones de cada palabra; por tanto, teníamos tres palabras del sonido consonántico 'ye' que por tres repeticiones hacía un total de nueve sonidos que por cuatro informantes hacían un total de 36 sonidos de cada realización. Se han desechado algunas palabras por diferentes motivos, por ejemplo hacer una pausa entre la palabra inicial y el resto de la frase o por alguna equivocación. Finalmente, hemos obtenido 33 realizaciones de cada ocurrencia para la estadística.

\subsection{Palabras estudidas}

- consonante 'ye' intervocálica: maya, raya, saya

- consonante 'ye' inicial absoluto: hielo, hierro, hierba

- consonantes aproximantes: daba, nada, haga

- semiconsonante: piano, diario, viaje

- fricativa labiodental [v], brasileña: divino, nova, ovella

- consonantes fricativas mates: caza, gafas, caja

- consonantes fricativas mates sonorizadas: jazmín, juzgar (en este caso se estudiaron 23 de las 24 posibles)

- fricativa sibilante [s]: casa, es una, gafas.

\subsection{Método de análisis: cruces por cero}

Los cruces por cero (en inglés, zero crossing) indican el número de veces que una señal continua toma el valor de cero o dicho de otra forma: hay un cruce por cero cada vez que la señal cambia de positivo a negativo o viceversa. En la figura 3 aparece un oscilograma con una onda simple que posee tres cruces por la línea cero. Comienza en la parte negativa y cruza a la positiva, a continuación volverá a cruzar hacia la parte negativa y, por último vuelve a la positiva. 


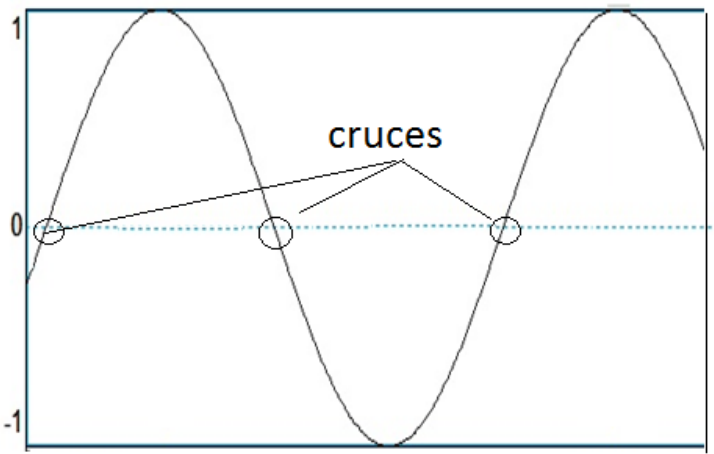

Fig. 3. Señal continua con señalización de tres cruces por cero

Las señales con mayor frecuencia presentan un mayor valor de esta característica. La duración de la señal también influye, pues a mayor duración mayor número de cruces habrá (véase figura 4).

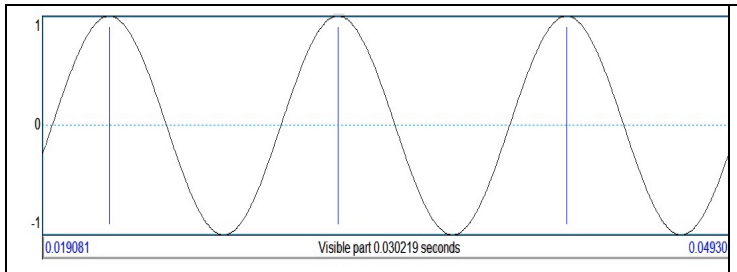

a) Se muestran $30 \mathrm{~ms}$ de una onda de $100 \mathrm{~Hz}: 6$ cruces

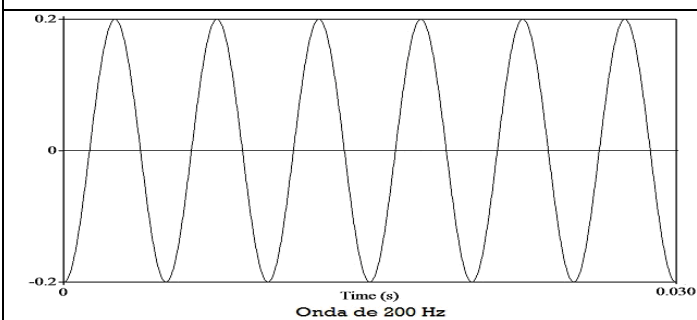

c) Se muestran $30 \mathrm{~ms}$, pero con frecuencia doble $(200 \mathrm{~Hz}): 12$ cruces

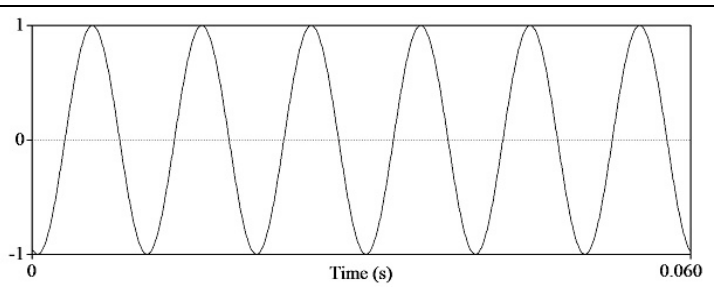

b) Se muestran $60 \mathrm{~ms}$ de una onda de $100 \mathrm{~Hz}: 12$ cruces

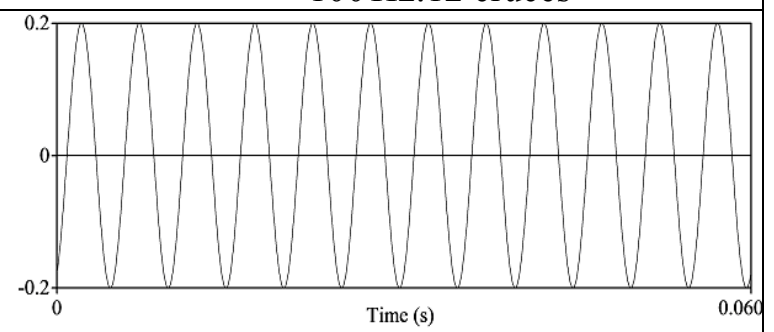

d) Se muestran $60 \mathrm{~ms}$ de una onda de $200 \mathrm{~Hz}: 24$ cruces

Fig. 4. Oscilogramas de ondas simples donde se ve que los cruces por cero cambian según la duración y la frecuencia

En la figura 4 se observa la influencia que ejercen tanto la duración como la frecuencia en los cruces por cero: tanto si duplicamos el tiempo como la frecuencia se duplican los cruces por cero. Esto significa que en el experimento tendremos que controlar estas variables. De hecho, hemos intentado minimizar la influencia de la frecuencia grabando solo voces femeninas, pues estas tendrán mayor número de cruces que las voces masculinas al ser voces más agudas por regla general. No obstante, dentro 
de las voces femeninas las hay más y menos agudas. En estadística, la desviación estándar nos dirá el grado de homogeneidad existente entre estas voces femeninas. Por otra parte, el impacto de la duración lo hemos controlado mediante un script de Praat (realizado por Román y Elvira García, 2013) que realiza la medición de los cruces en 30 milésimas siguiendo un «TextGrid» donde hemos establecido las marcas en el centro del sonido que queremos analizar. Por ejemplo, el script nos da la siguiente información de la ventana a) de la figura 4:

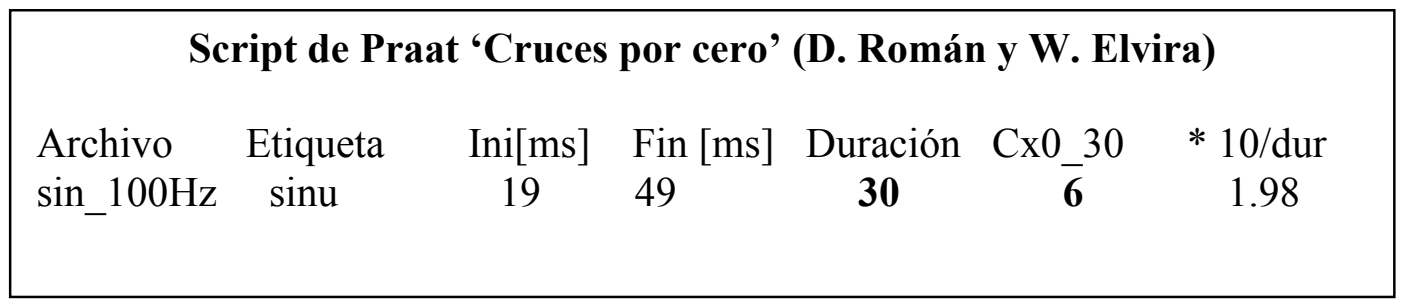

En primer lugar nos dice que el análisis es del archivo 'sin_100Hz' con etiqueta 'sinu'(-soidal), ha comenzado a contar a las $19 \mathrm{~ms}$ de todo el sonido y ha acabado a las $49 \mathrm{~ms}$ (en el «TextGrid» la primera barra separadora estaba colocada a las $19 \mathrm{~ms}$, el 'script' no tiene en cuenta cuándo está colocada la segunda, pues analiza solo las 30 primeras $\mathrm{ms})$; por tanto, la duración ha sido $30 \mathrm{~ms}(49-19=30)$ de análisis de cruces por cero. El resultado $\mathrm{Cx} 0 \_30(\mathrm{C}=$ cruces $\mathrm{x}$ cero de $30 \mathrm{~ms})$ es de 6; como se puede comprobar en la ventana a), es correcto el recuento de cruces, por lo que podemos estar seguros de los datos que nos proporciona el 'script'. Nosotros tendremos en cuenta solo el dato de los cruces en $30 \mathrm{~ms}$, pues el 'script' proporciona otro dato estandarizador: multiplica por 10 el número de cruces y lo divide por el tiempo total existente entre las dos marcas del «textgrid», por tanto no se atiene a las $30 \mathrm{~ms}$. En el caso que estamos analizando se nos dice que el valor es de 1,98; de hecho si hiciéramos la operación con los $30 \mathrm{~ms}$, nos daría lo siguiente: $\left(6^{*} 10\right) / 30=2$, prácticamente las 1,98 que nos ha proporcionado; si este mismo análisis lo hiciéramos en la ventana b), obtendríamos el mismo resultado: $(12 * 10) / 60=2$, lo cual demuestra que este dato también serviría para estandarizar el resultado y para evitar la influencia de la duración sobre el número de los cruces por cero. En realidad había un poco más de $30 \mathrm{~ms}$ entre las dos marcas del «TextGrid», pues $\left(6^{*} 10\right) / 30,30=1,98$, que es el dato que nos está dando el script. En el estudio actual no hemos tenido en cuenta este dato, solo tomaremos en consideración los cruces por cero en $30 \mathrm{~ms}$.

El ruido también genera un gran número de cruces por cero como se puede ver en la figura 5. El Praat utiliza una fórmula que añade ruido a la señal y posee entonces la forma que presenta el oscilograma de la izquierda de la figura 5. Como se ve, la señal no cruza de una manera simple por cero sino que lo hace repetitivamente. En la parte derecha de la figura hemos hecho un zoom para que se vea que en cada punto pasa por cero varias veces; de hecho el script nos indica que en $30 \mathrm{~ms}$ ha pasado 93 veces por cero. Por tanto, esta es una buena medida del ruido de una señal y, por tanto, es una medida excelente para indicar si un sonido es fricativo o no. 


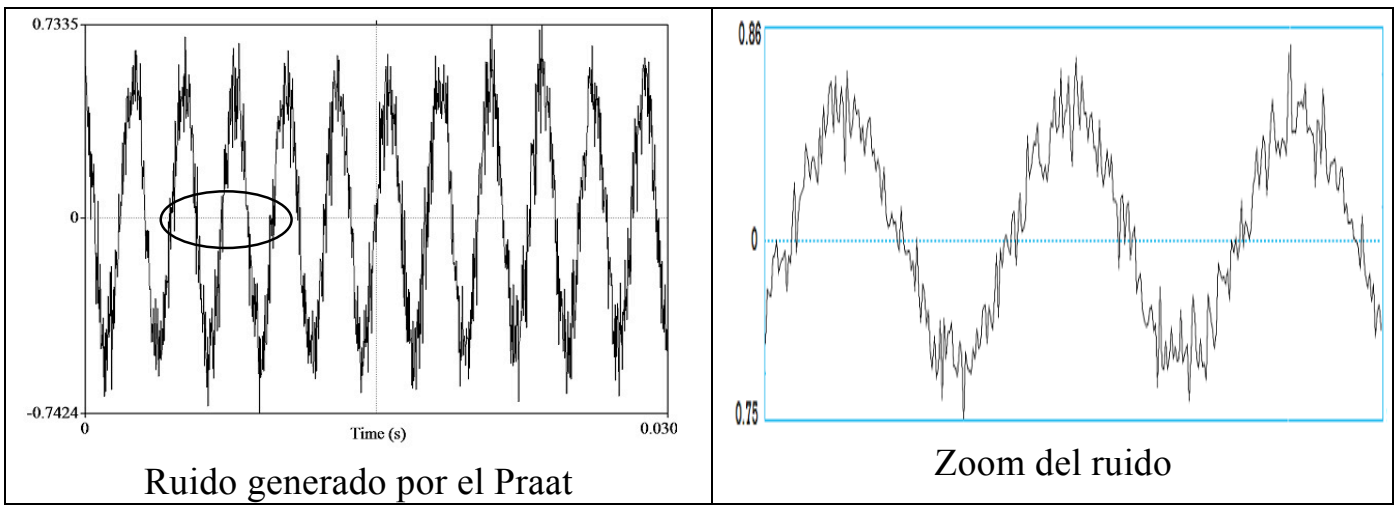

Fig. 5. cruces por cero en el ruido

En la figura 6 presentamos una pequeña muestra de los cruces por cero de una consonante aproximante 'ye', en la parte izquierda y de una fricativa interdental sonorizada en la parte derecha. Se observará que la aproximante pasa muy pocas veces por cero, mientras que la fricativa tiene muchos pasos por cero, sobre todo en la parte de la derecha del gráfico que se señala con una flecha.

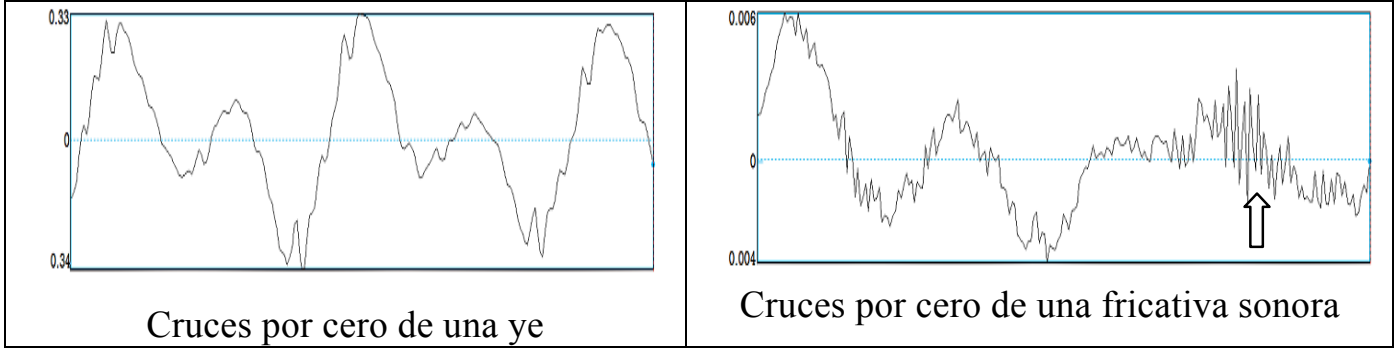

Fig. 6. Diferencia de cantidad de cruces en una aproximante frente a una fricativa sonora

Santagada y Gurlekian (1989) fueron los primeros en utilizar el método de los cruces por cero para ver en qué medida los alófonos no oclusivos de /b, d, g/ eran aproximantes o fricativos. Ellos lo indican con estas palabras «...to quantify the periodicity degree and the noise level present in the consonantas $/ \mathrm{b} /, / \mathrm{d} /$, and $/ \mathrm{g} /$, we have selected the processing tecniques ... such as the zero crossing rate estimation... (Franco, 1983)...» (p. 366). Y continúan diciendo que «...a high number of zero crossings is an indication that the signal presents typical characteristics of noisy sounds» y, por tanto, de fricación.

Ejemplo de sus resultados:

$$
\text { más ruido }
$$

contexto: /a_a/

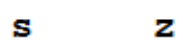

1 menos ruido

d

g a 
No cabe la menor duda de que a partir de /1/ no existe la fricación. No obstante ellos no tienen en cuenta fricativas no sibilantes, pues la sibilancia aumenta considerablemente los cruces por cero como se verá en nuestros resultados. En el ejemplo, ellos dicen "más ruido», lo que significa mayor número de cruces por cero y «menos ruido» es equivalente a menor número de cruces. Esa gradación tiene que ver con el número de cruces por cero, muy alto en las sibilantes [s, z] y muy bajo en las aproximantes y vocales.

\subsection{Figuras prototípicas de los sonidos estudiados}
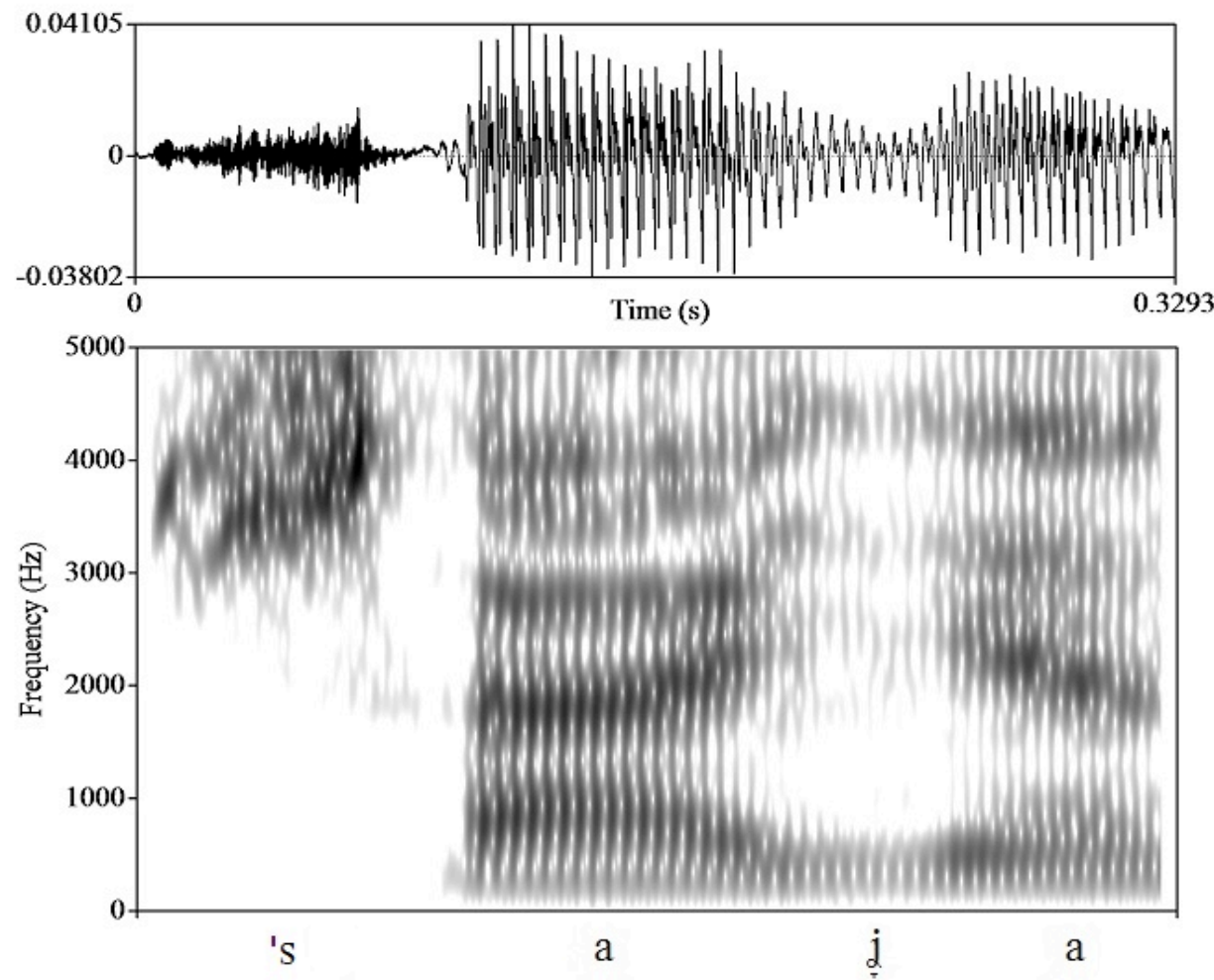

Fig. 7. Oscilograma y espectrograma de la palabra saya

En la figura 7 la consonante 'ye' aparece con F2 y F3 muy debilitados y no posee nada de ruido tal como se observa en el oscilograma y en el espectrograma. Esta es, pues, la imagen prototípica de una consonante aproximante.

En la figura 8 se colocan dos imágenes: aproximante a la izquierda y fricativa sonora a la derecha, de esta forma se puede ver claramente el distinto aspecto que ofrecen esas dos estructuras fonéticas. La apariencia del ruido es una masa amorfa mezclada con estrías muy débiles, aunque en esta imagen la sonoridad se ha debilitado bastante en el centro como se puede ver en la propia barra de sonoridad. 


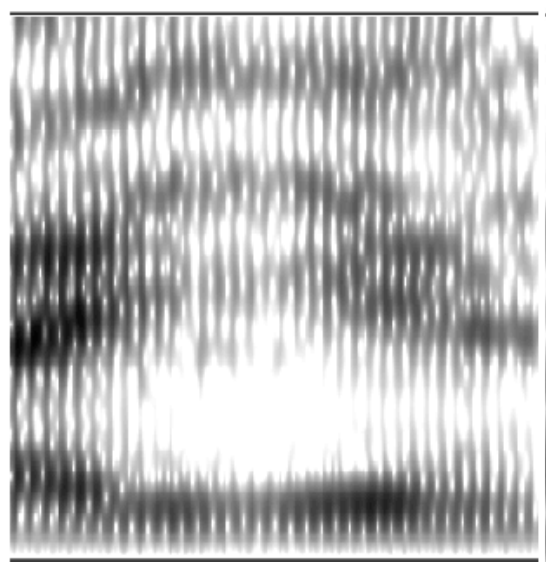

a j

a

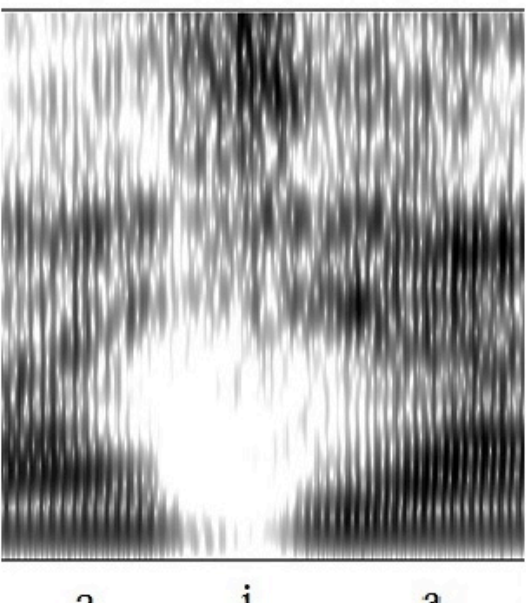

Fig. 8. Aproximante vs. fricativa sonora.

En la fig. 9 presentamos una palabra portuguesa en la voz de una brasileña. Se trata de la palabra divino. En ella se puede apreciar la pronunciación intervocálica de una verdadera fricativa sonora mate: la [v]. Además, la palatalización de la $<\mathrm{d}>$ inicial ante la vocal anterior hace que se pronuncie como una africada sonora alveolopalatal: [ब]了]; por tanto, con una distensión fricativa sonora sibilante evidente. Sirvan estas imágenes espectrográficas como muestra de cómo son las fricativas sonoras intervocálicas y las africadas sonoras propiamente dichas.
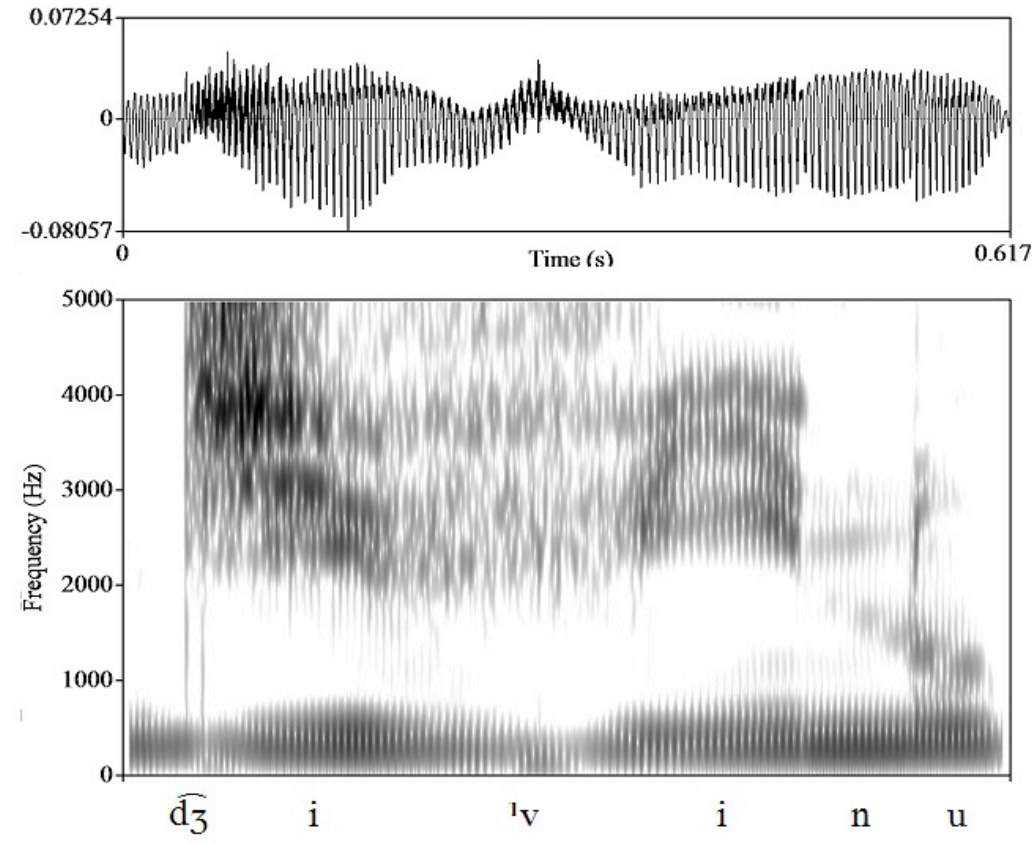

Fig. 9 Pronunciación brasileña de la palabra divino. 
A continuación presentamos una doble articulación; ya que, si no posee una distensión fricativa, no podemos llamarla africada (fig. 10).

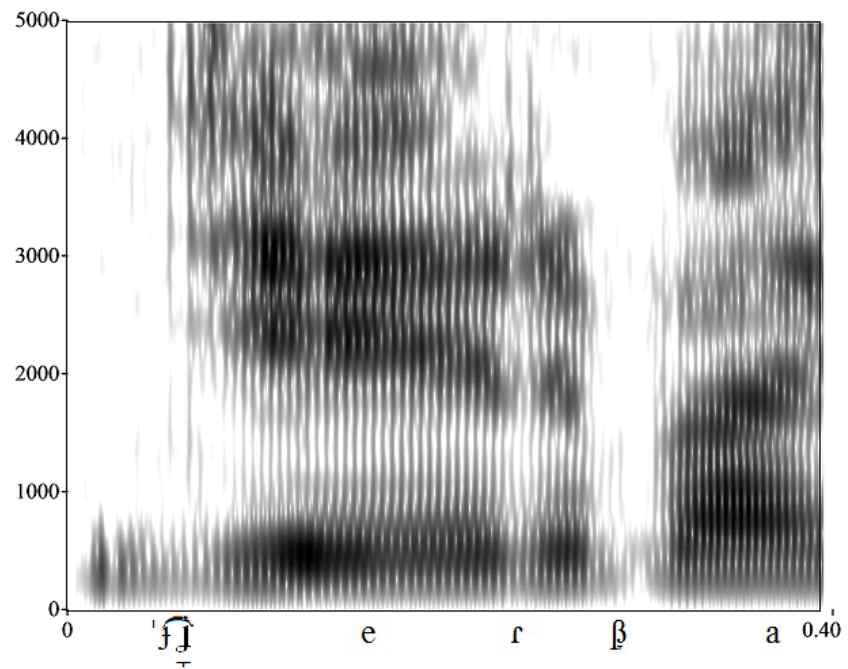

Fig. 10. Espectrograma de la palabra hierba en inicio absoluto.

Tras la explosión no aparece nada de ruido: solo las estrías débiles de cualquier aproximante.

\section{RESULTADOS}

A continuación se expone la tabla 1, extraída de los resultados arrojados por el paquete estadístico SPSS: etiquetas, número de datos entrados, mínimo y máximo de cruces por cero, media aritmética y, por último, la desviación estándar.

\section{Descriptive Statistics}

\begin{tabular}{|l|r|r|r|r|r|}
\hline & N & Minimum & Maximum & Mean & Std. Deviation \\
\hline ye_apr & 33 & 15 & 37 & 24,12 & 6,412 \\
ye_dob_art & 33 & 11 & 43 & 27,09 & 7,609 \\
bdg_ap & 33 & 13 & 45 & 27,21 & 8,778 \\
ies & 33 & 17 & 48 & 31,39 & 8,653 \\
fric_son & 23 & 33 & 102 & 67,09 & 19,619 \\
ves_labden & 33 & 31 & 233 & 123,52 & 59,963 \\
fric_sor_m & 33 & 90 & 249 & 153,94 & 39,024 \\
fric_sor_e & 33 & 239 & 455 & 326,42 & 48,116 \\
\hline
\end{tabular}

Tabla 1. Datos estadísticos proporcionados por el SPSS 
Como se ve en la tabla 1 hay cuatro conjuntos de datos muy próximos: 1) la consonante 'ye' en la posición intervocálica ('ye_apr': maya, saya, raya); 2) la doble articulación de 'ye' en posición inicial ('ye_dob-art': hielo, hierro, hierba); 3) las consonantes aproximantes bilabial, interdental y velar ('bdg_ap': daba, nada, haga), y 4) las vocales/semivocales ('íes': piano, diario, viaje). La intención primera fue estudiar la semiconsonante [j], pero resultó que la mayor parte de realizaciones se produjeron con hiato inicial, por lo que resultaron ser vocales [i]. Las medias de los cruces por cero son: 24-27-27-31, con datos enteros respectivamente. Y las desviaciones están muy próximas también: 6-7-8-8. Como se puede apreciar, estas medias están tan próximas que se adivina una naturaleza fonética común en cuanto a la ausencia de ruido, ya que los cruces no son muy elevados.

Las fricativas sonorizadas ('fric_son': jazmín y juzgar) poseen una media de 67 cruces e inmediatamente suben los cruces en las plenamente fricativas intervocálicas. La fricativa sonora labiodental brasileña posee 123 cruces ('ves_labden': divino, nova, ovella). Hasta aquí todos los sonidos estudiados eran sonoros.

Los sonidos sordos son los que más cruces presentan. Está claro que la vibración de las cuerdas vocales impone una cierta periodicidad que se manifiesta en un número bastante menor de cruces por cero. Además, hemos dividido las fricativas sordas en mates y estridentes porque pudimos ver que la sibilancia aumentaba el número de cruces. Las fricativas mates ('fric_sor_m': caza, gafas, caja) poseen una media de 153 cruces y la sibilante [s] ('fric_sor_e') posee 326 cruces, bastante más del doble. Esto nos está indicando que los cruces también sirven para saber si una fricativa es sibilante o no. Además las fricativas en general son las que poseen mayor desviación estándar: mates 39 y estridente 48. Siguiendo a Santagada y Gurlekian podríamos establecer la siguiente gradación:

\section{menos ruido}

ye_intervoc ye_dob_art fric_son

v_fric bdg vocal i

más ruido

Paired Samples Test

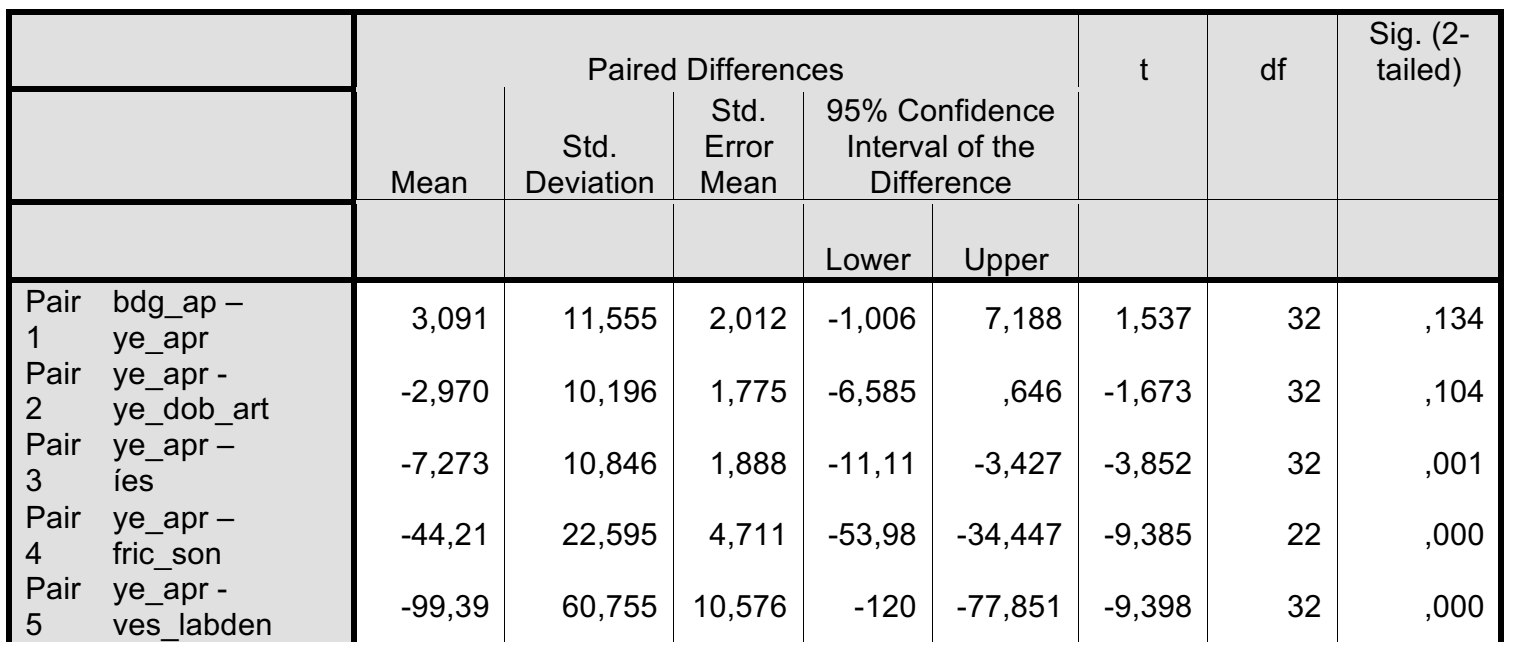




\begin{tabular}{|c|c|c|c|c|c|c|c|c|c|}
\hline $\begin{array}{l}\text { Pair } \\
6\end{array}$ & $\begin{array}{l}\text { ye_apr - } \\
\text { fric_sor_m }\end{array}$ & $-129,8$ & 39,008 & 6,790 & -143 & $-115,98$ & $-19,11$ & 32 & ,000 \\
\hline $\begin{array}{l}\text { Pair } \\
7\end{array}$ & $\begin{array}{l}\text { ye_apr- } \\
\text { fric_sor_e }\end{array}$ & $-302,3$ & 48,745 & 8,485 & -319 & $-285,01$ & $-35,62$ & 32 & ,000 \\
\hline $\begin{array}{l}\text { Pair } \\
8\end{array}$ & $\begin{array}{l}\text { bdg_ap-- } \\
\text { ye_dob_art }\end{array}$ & 121, & 11,036 & 1,921 & $-3,792$ & 4,034 & ,063 & 32 & 950 \\
\hline $\begin{array}{l}\text { Pair } \\
9\end{array}$ & $\begin{array}{l}\text { ye_dob_art - } \\
\text { fric_son }\end{array}$ & $-42,30$ & 20,630 & 4,302 & -51 & $-33,383$ & $-9,835$ & 22 & ,000 \\
\hline $\begin{array}{l}\text { Pair } \\
10\end{array}$ & $\begin{array}{l}\text { ye_dob_art - } \\
\text { ves_labden }\end{array}$ & $-96,42$ & 58,098 & 10,114 & -117 & $-75,824$ & $-9,534$ & 32 & ,000 \\
\hline
\end{tabular}

Tabla 2. Prueba de t-test por parejas

Aplicamos la prueba de t-test por parejas para saber si existían diferencias significativas entre estos conjuntos de sonidos. Situándonos en la última columna que nos da la significación, consideraremos que no existen diferencias significativas siempre que se supere el 0,05 ; por tanto, no hay diferencias significativas en la pareja 1 , 'bdg_aproximantes' y 'ye_aproximante', tampoco la hay entre 'ye_aproximante y 'ye doble articulación', ni entre 'ye_doble articulación' y 'bdg_aproximantes'; es decir, estos conjuntos poseen conjuntos de cruces por cero que son básicamente los mismos. No existen pues diferencias entre la consonante 'ye' aproximante intervocálica y la consonante 'ye' que aparece en inicio absoluto y que decimos que es una doble articulación (sig. 0,104), por ejemplo saya vs. hielo. Tampoco existen diferencias significativas entre la consonante 'ye', intervocálica o doble articulación, y los alófonos aproximantes de /b, d, g/ (sig. 0,134 y 0,950). Existen diferencias significativas entre todos los demás pares enfrentados: ye_aproximante y vocal /i/, en este caso las medias de cruces por cero en $30 \mathrm{~ms}$ eran 24 y 31 , respectivamente; ye_aproximante y fricativa sonorizada; ye_aproximante y v_labiodental brasileña; etc.

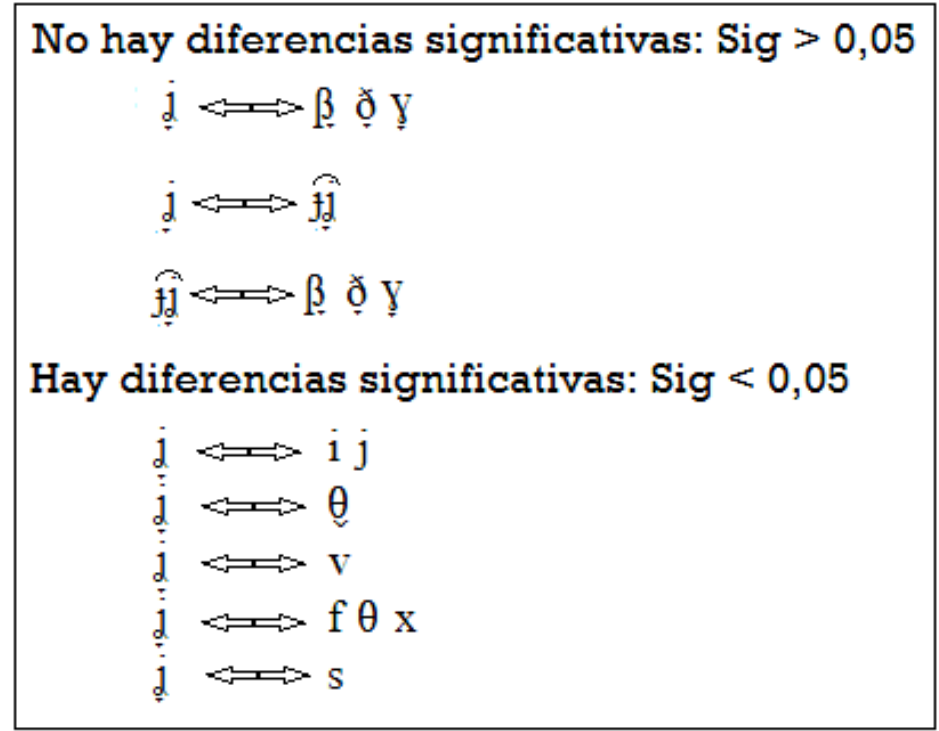

Tabla 3. Resumen de las diferencias significativas y no significativas más importantes. 


\section{CONCLUSIONES}

Los datos proporcionados por los cruces por cero en $30 \mathrm{~ms}$ para la 'ye' son los

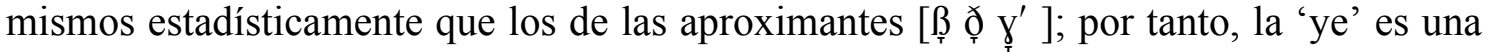
articulación aproximante.

Además, los electropalatogramas indican que es un sonido claramente palatal, en contra de todos los que afirman que es prepalatal o alveolopalatal.

Sucede lo mismo con el alófono africado, o mejor 'doble articulación' como hemos venido llamándolo, pues su segundo elemento no es fricativo, por lo que hay que rechazar la transcripción [ $\overline{\mathrm{d}} 3$ ] que muchos utilizan. Nuestra propuesta ha sido siempre [j]'], porque tras la explosión se presenta habitualmente una aproximante (Martínez Celdrán y Fernández Planas, 2001).

\section{REFERENCIAS BIBLIOGRÁFICAS}

Aguilar, L. (1997): De la vocal a la consonante, Santiago de Compostela, Universidade de Santiago de Compostela.

Canellada, M. J. y J. K. Madsen (1987): Pronunciación del español, Madrid, Castalia.

FACE, T. L. (2003): «Consonant strength innovations across the Spanish-speaking world: evidence and implicatios for a usage-based model of phonology», en Coleman, D. W., W. J. Sullivan y A. Lommel, eds., LACUS Forum XXIX and the Real World, Houston, LACUS, 25-35.

Hualde, J. I. (2014): Los sonidos del español, Cambridge, Cambridge University Press, $<$ http://dx.doi.org/10.1017/cbo9780511719943 $>$.

Martínez CEldrÁN, E. (2008): «Some Chimeras of Traditional Spanish Phonetics», en Colantoni, L. y J. Steele, Selected Proceedings of the $3^{\text {rd }}$ Conference on Laboratory Approaches to Spanish Phonology, Somerville, Cascadilla Proceedings Project, 32-46.

Martínez Celdrán, E. y A. M. Fernández Planas (2001): «Propuesta de transcripción para la africada palatal sonora del español», Estudios de Fonética Experimental, vol. XI, 173-190.

Martínez Celdrán, E. y A. M. Fernández Planas (2007): Manual de fonética española, Barcelona, Ariel (segunda edición, 2013).

NAVArRo TomÁs, T. (1934): «Rehilamiento», Revista de Filología Española, vol. XXI, 274-279.

NAVArro Tomás, T. (1946): Estudios de fonología española, Nueva York, Las Américas Publishing Company, (segunda edición, 1966).

RAE (2011): Nueva gramática de la lengua española. Fonética y fonología, Barcelona, Espasa Libros, S.L.U.

RECASENS, D. (2014): Fonètica $i$ fonologia experimentals del català. Vocals $i$ consonants, Barcelona, Institut d'Estudis Catalans.

RomÁn, D. y W. Elvira García (2013): «Cruces por cero», script de Praat. 
Santagada, M. y J. A. Gurlekian (1989): «Spanish Voiced Stops in VCV Contexts: are they Fricative Variants or Approximants?», Revue de Phonétique Apliquée, 91-92-93, 363-375.

SAROÏHANDY, J. (1895): «Estudios de fonética castellana», por Araujo, F., Romania, vol. XXIV, 298-303. 